\title{
Opportunities and limits of recycling: A dynamic-model-based analysis
}

\author{
Markus Reuter and Antoinette van Schaik
}

\begin{abstract}
Ensuring the continued availability of materials for manufactured products requires comprehensive systems to recapture resources from end-of-life and wastewater products. To design such systems, it is critical to account for the complexities of extracting desired materials from multicomponent products and waste streams. Toward that end, we have constructed dynamic simulation-optimization models that accurately describe the recovery of materials and energy from products, residues, and wastewater sludges. These models incorporate fundamental principles such as the second law of thermodynamics, as well as detailed, empirically based descriptions of the mechanical separation of materials at the particulate level. They also account for the evolution of the recycling system over time. Including these real-world details and constraints enables realistic comparisons of recycling rates for different products and technological options and accurate assessments of options for improvement. We have applied this methodology to the recycling of complex, multimaterial products, specifically cars and electronic wastes, as well as wastewater and surface-water systems. This analysis clarifies how product design, recycling technology, and process metallurgy affect recycling rates and water quality. By linking these principles to technology-based design-for-recycling systems, we aim to provide a rigorous basis to reveal the opportunities and limits of recycling to ensure the supply of critical elements. These tools will also provide information to help policymakers reach appropriate decisions on how to design and run these systems and allow the general public to make informed choices when selecting products and services.
\end{abstract}

\section{Introduction}

"Natural resources underpin the functioning of the European and global economy and our quality of life," declares A resourceefficient Europe-Flagship initiative under the Europe 2020 strategy. ${ }^{1}$ Reliable access to critical raw materials is a persistent challenge for resource-dependent countries, and this initiative supports smarter use of natural resources to achieve sustainable growth. For example, a European Union document discussing scarce materials ${ }^{2}$ (Table I) highlights rare earths (REs), such as neodymium for magnets. REs enable products that are important for sustainable development, such as modern transport, wind-power energy, and energy-efficient lighting.

Like other elements, REs can be obtained not only from minerals but also from various consumer and industrial products that use them, such as electronic waste. Closure of material cycles and minimization of waste creation can achieve prudent use of resources and help secure supplies of critical materials. Metallurgy, which provides these elements from natural ores, plays a crucial role in enabling sustainability by also recovering them from manufactured products. Principles of physics, chemistry, engineering, thermodynamics, and economics all constrain the extraction of materials, metals, and energy from end-of-life (EOL) consumer goods, wastes, residues, wastewater sludges, and other sources.

The design of products profoundly affects the potential recyclability of the resources they contain. The philosophy of design for recycling (DfR) aims to improve this recyclability, often using generally accepted methodologies such as material flow analysis (MFA) and life-cycle assessment (LCA). However, an extensive review by Reuter ${ }^{3}$ concluded that these methods have not been implemented in enough detail to link to computer-aided design (CAD) systems to expose the full opportunities and limits of recycling, as these methodologies do not distinguish between metal-/material- and product-centric views of recycling.

The assessment of the recycling potential of each design should be based on established principles, including how the liberation of materials during breakage depends on the material 
Table I. List of critical raw materials identified by the European Union (in alphabetical order). ${ }^{2}$

\begin{tabular}{|l|l|}
\hline Antimony & Indium \\
\hline Berylium & Magnesium \\
\hline Cobalt & Niobium \\
\hline Fluorspar & Platinum-group metals \\
\hline Gallium & Rare earths \\
\hline Germanium & Tantalum \\
\hline Graphite & Tungsten \\
\hline
\end{tabular}

a Platinum-group metals include platinum, palladium, iridium, rhodium, ruthenium, and osmium.

${ }^{\mathrm{b}}$ Rare earths include yttrium, scandium, and the lanthanides (lanthanum, cerium, praseodymium, neodymium, promethium, samarium, europium, gadolinium, terbium, dysprosium, holmium, erbium, thulium, ytterbium, and lutetium).

connections and particulate characteristics of the recyclate flows (recycled material that will be used to form new products), the physics and chemistry of sorting, and the thermodynamics of high-temperature processing and resource recovery.

These physical separation steps and the closely linked metallurgical processing steps are keys to recycling.

Therefore, we have developed process-simulation methods and applied them to the complex liberation of materials from particles during shredding and physical recycling separation technology. Many of the parameters that characterize these processes, including particle size, material combinations (liberated, mixed, and/or joined), chemical interactions, and physical properties, vary widely. In addition, the distributions of these parameters often deviate from the normal distributions assumed in simple models. These details must be included if the recycling of waste and EOL products is to be modeled well enough to predict the quality of the recyclates. This quality determines their economic value, and if it is too low, the recyclates will be discarded, making it impossible to achieve closed-loop material cycles. Many simpler models do not capture the particulate nature of recyclates and, hence, their quality. These features are crucial in predicting and improving recycling system performance and thereby enabling sustainable product designs and the closure of material cycles.

To address the deficiencies in the modeling of recycling systems, we have drawn on our experience in simulating classical mineral and metallurgical processing systems to develop first-principles models for complex recycling systems for cars and electronic waste. We have also extended this theoretical foundation to encompass the impact of recycling and product design on surface-water and wastewater quality. This article briefly reviews these dynamic simulation-optimization models and their role in assessing and improving product design and recycling systems.

To illustrate our methodology, we describe three examples of industrial applications. In the first, we applied our approach to electronic-waste recycling at Wecycle (formerly NVMP) in the Netherlands, ${ }^{4,5}$ to predict recycling rates for various electronic consumer products and to show how resource efficiency can be improved. Second, the approach was used in the automotive industry ${ }^{6-9}$ to predict the recycling rate of a SuperLIGHT-CAR (SLC) design. Finally, we used our dynamic-modeling approach for a governmental water board in the Netherlands, ${ }^{10}$ to analyze the use of metallurgical processing to remove phosphate from wastewater and return the treated water to the resource cycle.

At their core, these efforts and the associated resourcesystem models aim to maximize resource efficiency and help industry to provide customers with the most environmentally friendly products while safeguarding the supply of critical elements, especially for high-technology applications, through recycling. The work quantifies the limits and opportunities of recycling for different products and related material flows. At the same time, it gives policymakers reliable information and helps the public make informed choices when selecting products and services.

\section{Dynamic recycling models}

Our recycling models provide a common language and tool for the evaluation, control, and optimization of recycling, enabling the calculation of statistical distributions of recycling rates. The results are detailed enough that they can be linked to software employing CAD principles. This framework identifies critical parameters in the design of products and recycling systems in view of recycling performance and resource efficiency. Linking to generally accepted methodologies such as MFA and LCA provides a powerful basis for quantifying recycling performance. ${ }^{3}$ Figure 1 illustrates the many processes that must be integrated into simulation and optimization models, as described in the following subsections.

\section{Physical separation}

Our models represent the complex liberation behavior of materials during shredding as a function of product-design characteristics, specifically the various material combinations and material connections in a product. This unique information and modeling were derived from a large body of data collected from various industrial shredder and recycling plant trials. Such practical knowledge is essential to fully model these systems, including the ways in which product design influences the enormously complex particulate streams emerging during recycling and, thus, recyclate quality and material recovery and loss. For example, the processes illustrated in Figure $\mathbf{2}$ might incompletely liberate pure materials from mixed particles, resulting in decreased separation efficiency. These models allow pinpointing of design deficiencies and opportunities related to recycling performance, in terms of both sorting and metallurgical recovery, to improve resource recovery from products such as cars and electronic waste. 


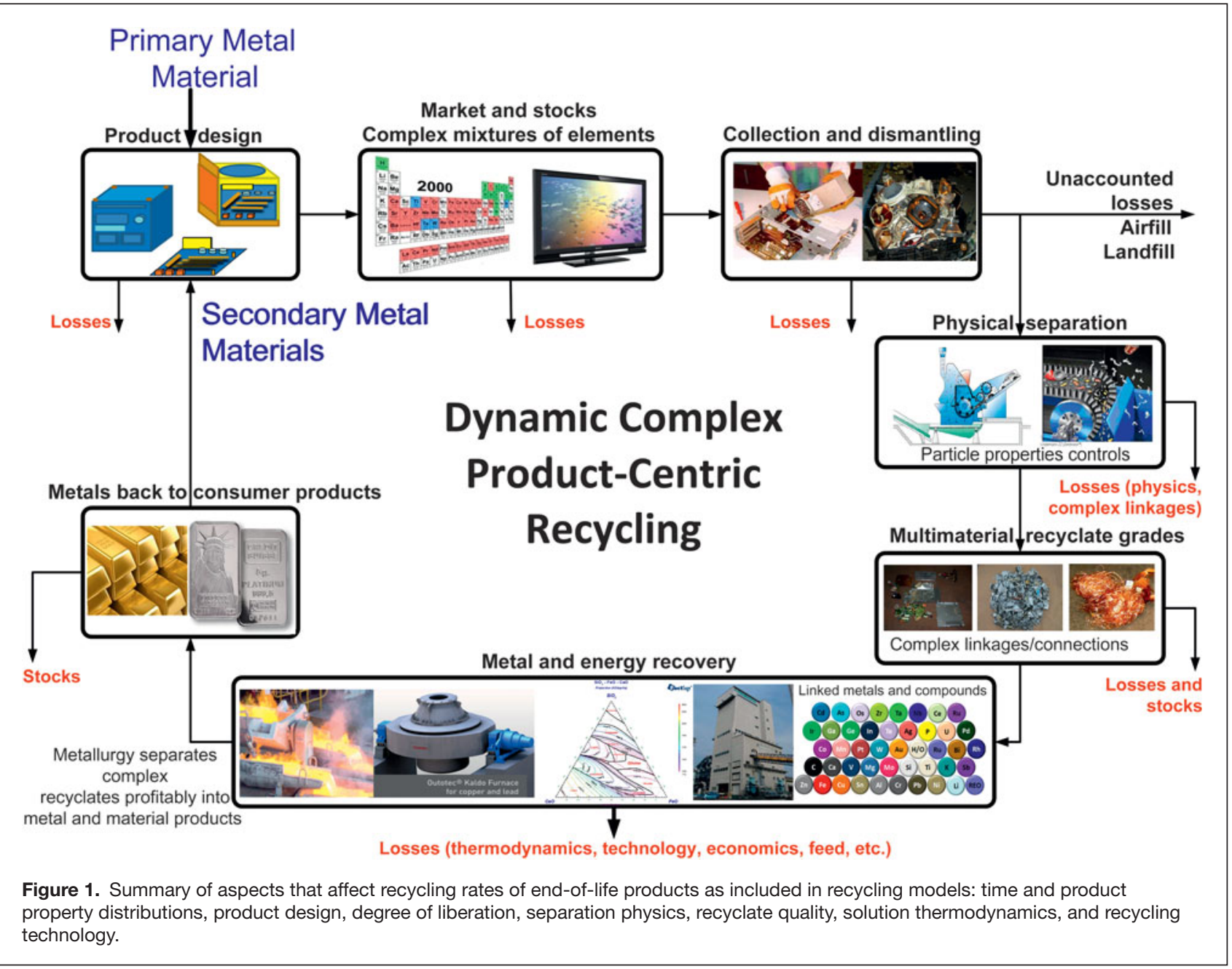

\section{Fundamental materials limits}

After mechanical separation, recovery in final treatments, such as metallurgical and thermal processing, is limited at the microscopic level by the second law of thermodynamics. Thus, material separation and recovery in different phases (metal, matte, ${ }^{*}$ speiss, ${ }^{\dagger}$ slag, ${ }^{\ddagger}$ flue dust, off-gas) are included in the models based on process thermodynamics and the chemical contents of and interactions among different elements/phases present in the recyclates obtained from dismantling and/or physical separation.

The simulation models are grounded in fundamental principles, as well as industrial experience with thermodynamics and associated process technology in a realistic economic environment. For example, Figure 3 shows the relative

\footnotetext{
* Matte is the molten metal sulfide phase generated by smelting nonferrous metals, such as copper and nickel.

${ }^{\dagger}$ Speiss is a molten phase consisting primarily of iron arsenide that is commonly encountered in lead smelting.

‡ Slag is a partially vitreous byproduct of smelting ore that usually consists of a mixture of metal oxides and silicon dioxide but can also contain metal sulfides and elemental metal.
}

stabilities of some oxides, which have a direct effect on their recovery and recycling rates. As another example, detailed materials properties such as oxidation states and vapor pressures also enter into the complexity associated with the recycling of many materials, such as indium-tin oxide from flat-panel displays, because of the various chemical species in which the constituent elements can appear when processed (see Figure 3b).

Exergy, the thermodynamically available energy in a particular environment, is introduced as an additional constraint in the optimization models. This allows the environmental performance of recycling systems to be evaluated and optimized by capturing the effect of recyclate quality, related to physical, metallurgical, and thermal processing and waste/losses in the system. ${ }^{3,4,9}$

\section{Software framework}

Recycling of complex, multimaterial consumer products demands an extended network of different types of processes to recover the different materials present. Figure 4 presents a software flow sheet illustrating the complexity and number of processes involved in resource recovery. These include manual 


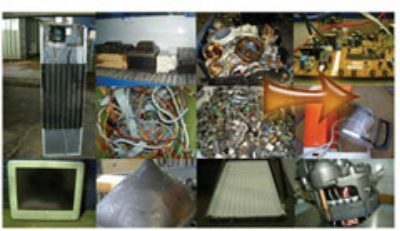

Design determines connections

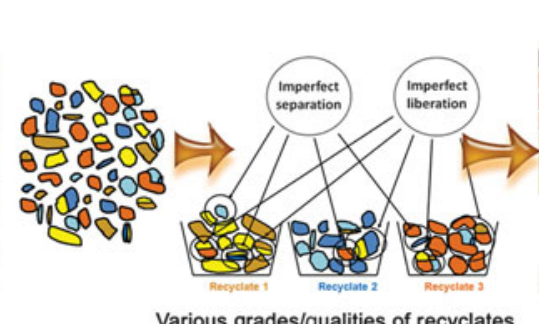

Various grades/qualities of recyclates

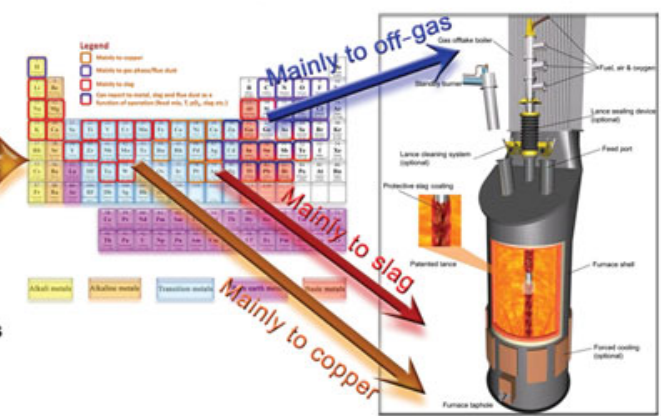

Figure 2. Product design and separation technology determine recyclate quality and recyclability resulting from liberation and separation of material particles. The models discussed in this article make it possible to link design with physical separation, metallurgical thermodynamics, and processing technology, providing the basis for quantifying design for sustainability and resource efficiency.

sorting and cleaning, shredding, physical sorting (e.g., magnetic separation, eddy current, density sorting, laser/color sorting), metallurgical processing for the different metals, plastic and inorganic treatment processes, and energy recovery. The selection and arrangement of processes determine the ultimate quality of recyclates and, hence, the resulting material and energy recovery.

Flow sheets including all possible recycling unit operations, such as that in Figure 4, provide a graphical and technological blueprint of models of recycling and illustrate the limits and possibilities of resource recovery. We have developed such flow sheets for several consumer products, including cars; refrigerators; cathode-ray-tube (CRT) televisions; washers and dryers; and small household appliances such as vacuum cleaners, toasters, mixers, and coffee makers. They provide a recycling simulation-optimization model for investigating existing and alternative processing routes for these products and/or product mixtures.

The input into any recycling system evolves over time because of changing (1) product design, (2) product composition (for example, in response to regulatory changes), (3) product-lifetime distributions, (4) consumer behavior, and (5) disposal behavior and stocks. All of these aspects have been included in our dynamic-modeling approach. The models can predict the recycling performance for different EOL systems and mixtures of products, recovery of precious or scarce materials, and leakage of minor elements for changing plant configurations (including dismantling), shredder settings, product designs, and recycling trends.

By capturing the effects of product design on liberation behavior, recyclate quality, separation and metallurgical process efficiency, and hence recyclability, this approach provides a

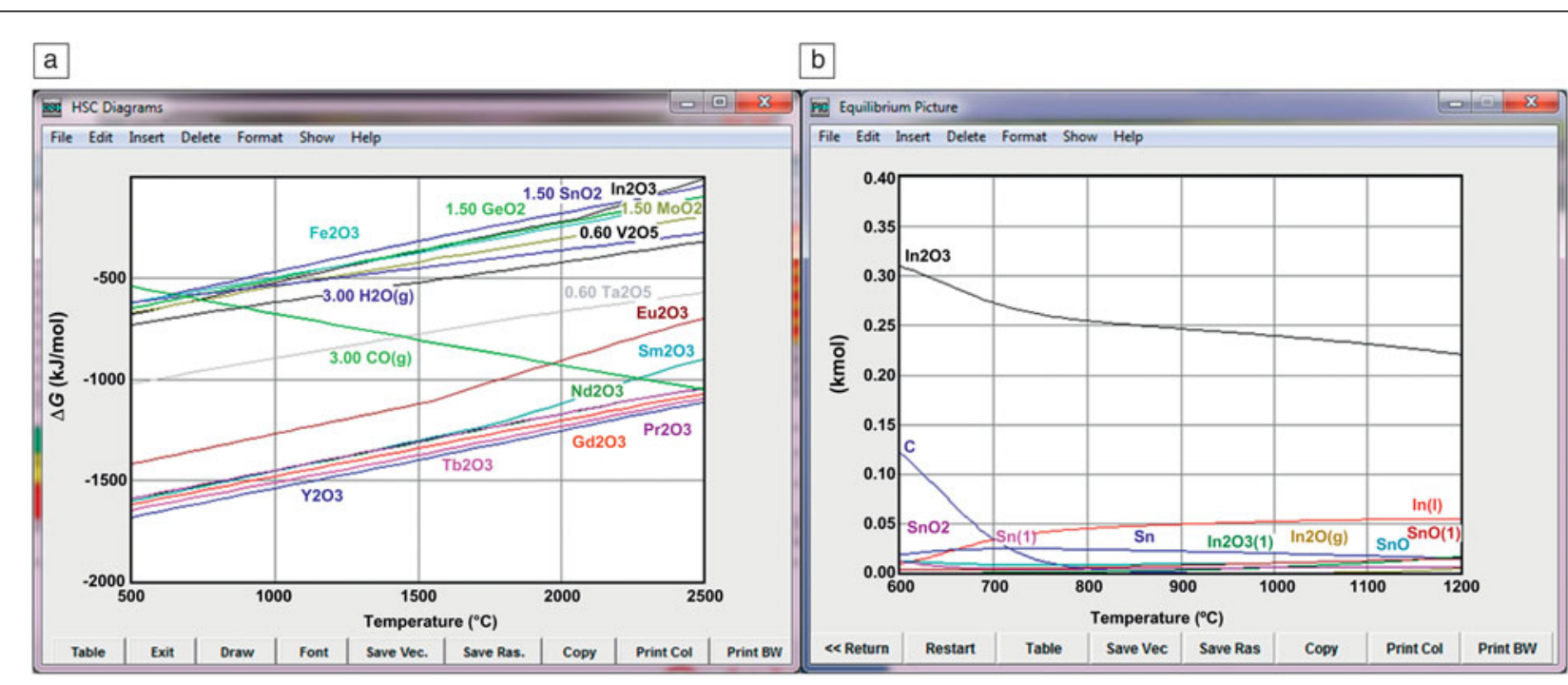

Figure 3. (a) Stabilities of some rare-earth and other oxides. The green $\mathrm{CO}$ line cutting through this plot defines where the oxides can be reduced by carbon. (b) Oxides of tin and indium under relatively oxidizing conditions, showing how well these elements can be recovered/ recycled. (If more carbon is added, conditions become more reducing, and more metal compounds are produced.) Plots created using the software program HSC Chemistry. ${ }^{11}$ 


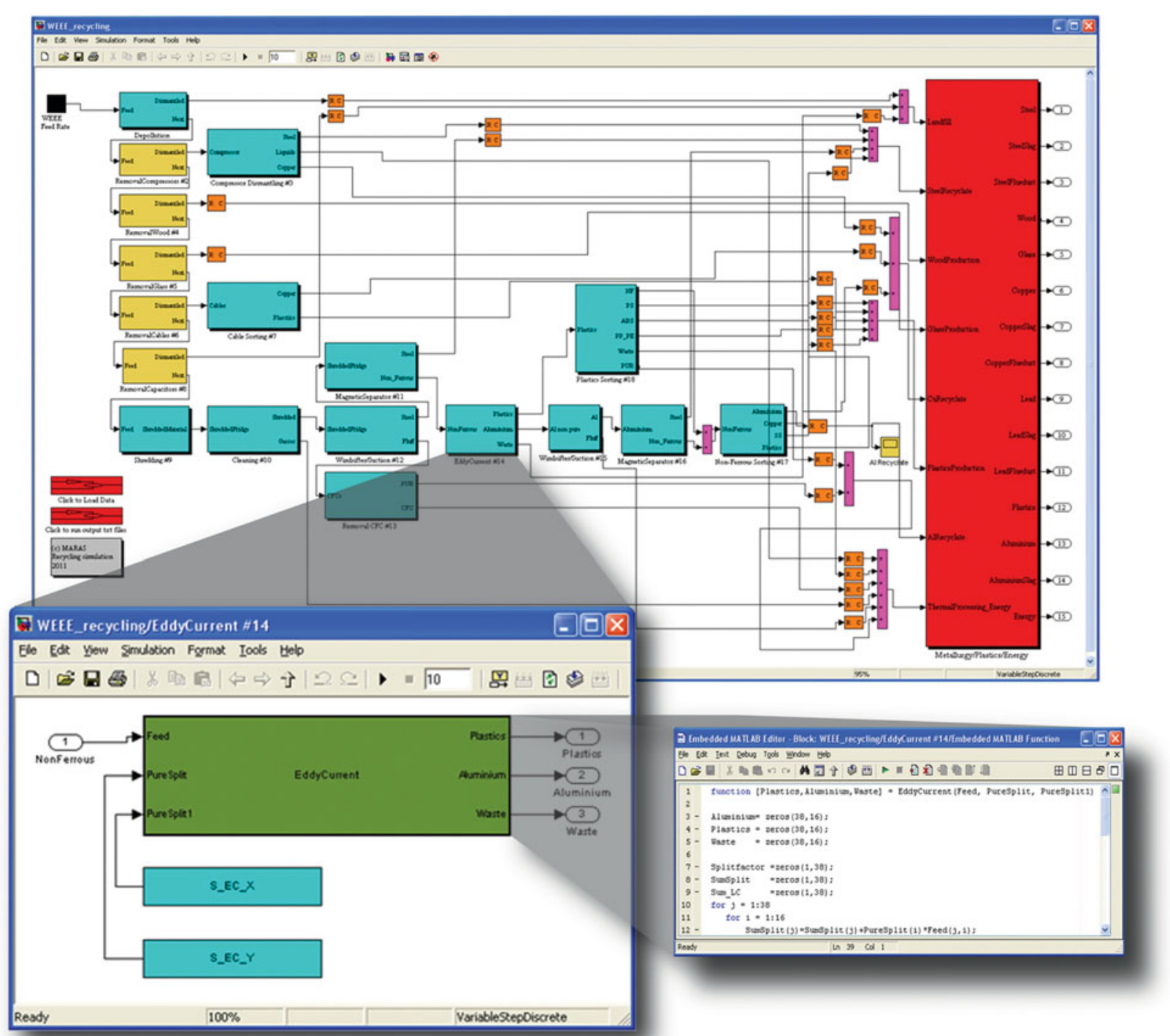

Figure 4. Example of a dynamic simulation model for the recycling of waste electrical and electronic equipment (WEEE) products including different manual and physical recycling options, a range of final treatment processes (e.g., metallurgical processing, thermal processing, plastic processing), and an example of the layered model structure showing the detail of different shredding and sorting options.

reliable basis for DfR. We have developed and applied fuzzy recycling models ${ }^{6,7}$ that capture the details of these rigorous recycling optimization models in a semiempirical way and linked them to CAD and LCA software to quantify recycling performance. ${ }^{6-9}$

\section{Applications of recycling system models}

Using the models described in the preceding section, we have performed the following industrial analyses:

- calculating and predicting the recycling and recovery rates of different types of electronic waste, EOL vehicles, and lightweight car-design concepts, including all individual materials in these products (e.g., compounds, alloys, composites, metals) in enough detail to provide an accurate picture of the losses, toxicology, and other characteristics;

- predicting the grade, in terms of both quality and composition, of all intermediate particulate recycling streams, including recyclates of steel, copper, and plastics, as well as recycling products such as metals, matte, slag, speiss, and flue dust; and

- predicting the recovery of scarce minor metals that are important for sustainable-energy and other high-technology industries, while tracking possible toxic or harmful components in recycling products and water.

The results of these analyses have provided critical information to manufacturers, consumers, and policymakers for use in making resource-efficient decisions about daunting and complex problems. 


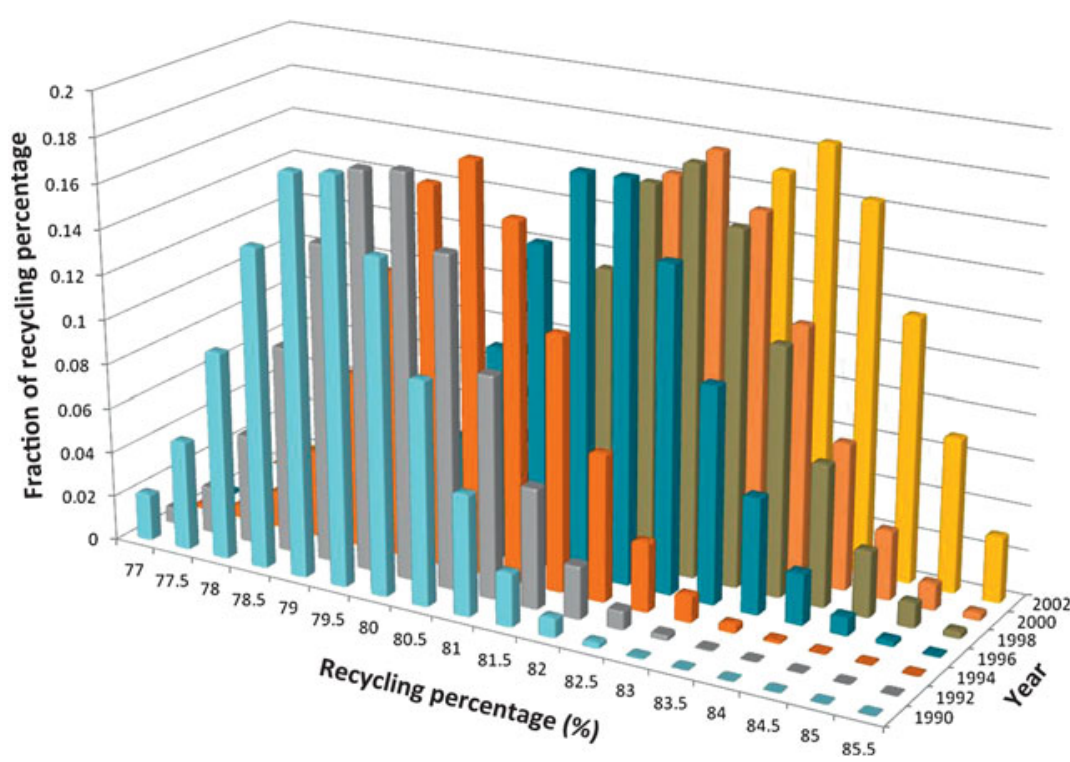

Figure 5. Dynamic recycling performance calculations for waste electrical and electronic equipment (WEEE) as a function of year, illustrating the evolution of recycling rates. For each year, modeling predicts a distribution of expected recycling rates, reflecting variations in properties such as material liberation, interlinked materials in complex products, quality of recyclates, range of products, and designs, to name a few.

such as $\mathrm{Pb}^{2+}, \mathrm{Mn}^{2+}$, or $\mathrm{Sb}^{3+}$ or an $\mathrm{RE}$ ion such as $\mathrm{Eu}^{2+}, \mathrm{Tb}^{3+}$, or $\mathrm{Ce}^{3+}$. Typically, the phosphors from fluorescent lamps are recovered easily from the inside of the tubing, whereas hydrometallurgical processing technology is used to recover the REs. ${ }^{14}$

In contrast, LEDs usually include compact combinations of organic materials and phosphors and require a different path. Indium and gallium are partially recovered in normal high-temperature smelting operations, for example, during WEEE/ copper scrap recycling. ${ }^{15}$ However, REs would be lost in the slag phase of the smelters.

Table II provides a qualitative overview of recycling/recovery possibilities for various critical materials in several types of WEEE. This table illustrates the influence of choices that can be made about recycling routes, such as the degree of dismantling. Extensive dismantling of RE-containing dielectric components on printed wiring boards or of getters ${ }^{\S}$ containing tungsten, cobalt, or tantalum from CRT televisions or lighting can recover materials that would otherwise be lost as contaminants to metal products or slag. A model, such as ours,

\section{Electronic waste/WEEE}

Valuable electronic waste, or the broader class of waste electrical and electronic equipment (WEEE), contains a variety of materials, ranging from commodity metals such as iron/steel, aluminum, and copper to critical minor elements including indium, antimony, cobalt, REs, precious metals, and platinumgroup metals. We have used our dynamic recycling models to predict the EOL recycling rates, and hence estimate the resource efficiency, of various products for all such materials, in both physical combinations and chemical compounds. ${ }^{4}$ This analysis was formulated for existing and alternative recycling routes, plant inputs (product mixtures, weights, and compositions that can change over time), and processing variations. A highly detailed description is required to cover the widely distributed and time-varying properties of recycling processes. ${ }^{3}$

Figure 5 shows an example of recycling performance simulations for large household appliances. The time-varying distribution of predicted recycling rates evolves in response to changing EOL product populations (different types of products from different production years), changing product weights and material compositions, and changing processing routes. The model captures the dynamic nature of product recycling and predicts recycling rates and resource availability. ${ }^{12}$

We have also used our simulation model to address the recycling of fluorescent lamps and light-emitting diodes (LEDs), both of which contain a variety of materials, including indium, gallium, and REs. Fluorescent powders, also called phosphors, generally consist of a host lattice [e.g., $\mathrm{Ca}_{5}\left(\mathrm{PO}_{4}\right)_{3}(\mathrm{Cl}, \mathrm{F})$, $\left.\mathrm{BaMgAl}_{10} \mathrm{O}_{17}, \mathrm{Y}_{2} \mathrm{O}_{5}, \mathrm{LaPO}_{4}, \mathrm{Y}_{3} \mathrm{Al}_{5} \mathrm{O}_{12}, \mathrm{YVO}_{5}\right]$ doped with a few percent of an activator. ${ }^{13}$ The activator can be a metal ion that is equipped with detailed material information allows users to assess different techniques. For example, the relative stability of oxides shown in Figure 3 indicates that the displayed REs form stable oxides that cannot generally be recovered by high-temperature means, but instead require hydrometallurgical processing. Table II also shows that the recovery of metals is ultimately dependent on their chemical properties, as metals with similar properties exhibit similar recoveries for various applications.

\section{Automobiles}

As part of the European Union's 6th Framework Programme, we used our model ${ }^{3}$ to simulate recycling for SuperLIGHTCAR (SLC) designs at the body-in-white (BIW) stage (i.e., comprising only the unpainted sheet metal frame of the vehicle). ${ }^{6,8}$ Specifically, we employed easy-to-use fuzzy models to (1) predict recycling/recovery rates with CAD software in "real design time" as a function of material usage, material combinations, and joints used and (2) provide detailed recycling data for environmental assessments using LCA software. In addition, the model results were used to guide $\mathrm{DfR}$ and recycling flow sheet configuration for multimaterial SLC designs. ${ }^{6,8}$

We also organized and managed a recycling trial in Belgium involving 1153 cars for the European automotive and recycling industries (see Figure 6). The objective was to measure, in a

\footnotetext{
$\S$ A getter is a deposit of reactive material that is deliberately placed inside a vacuum system, to complete and maintain the vacuum.
} 


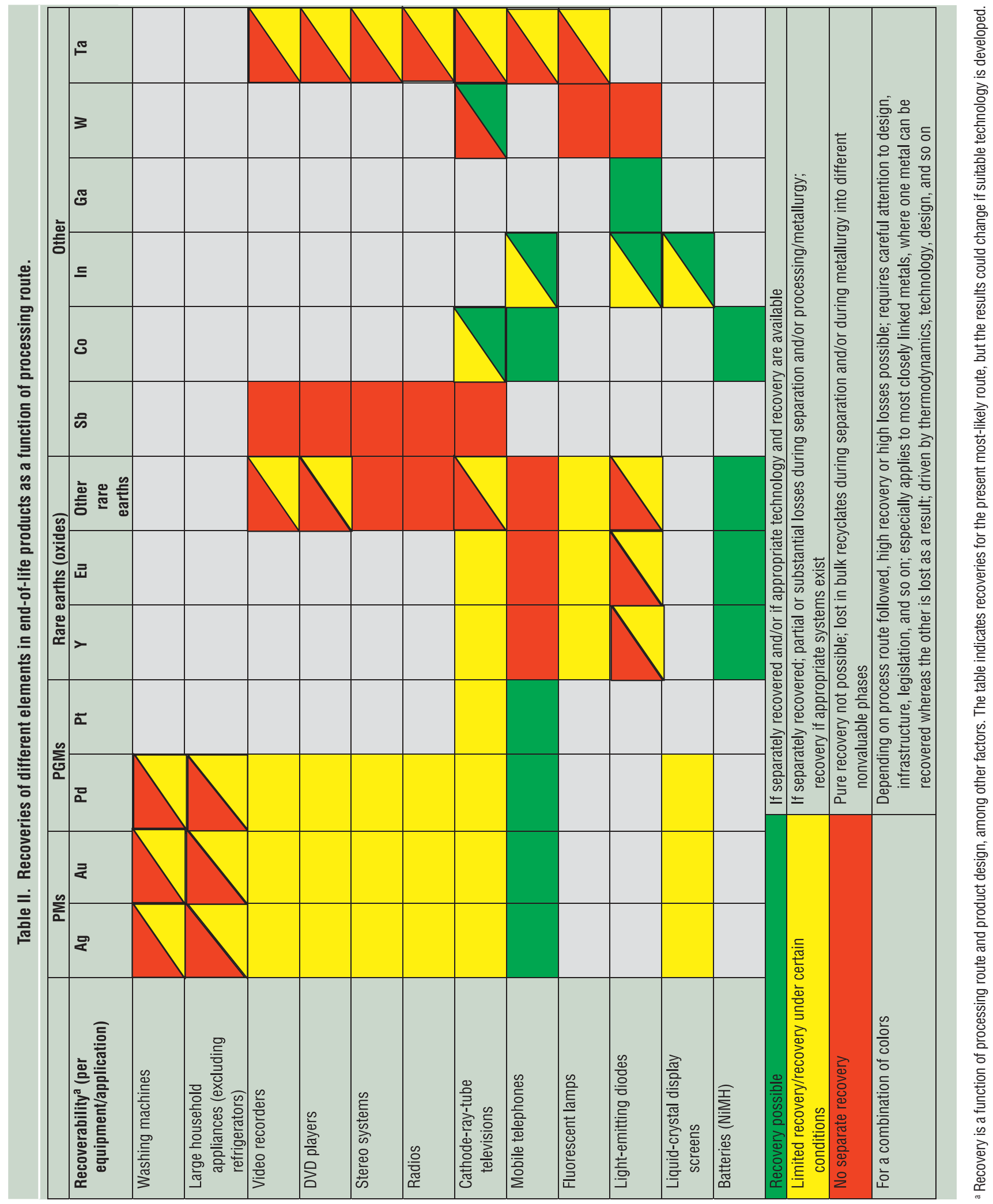




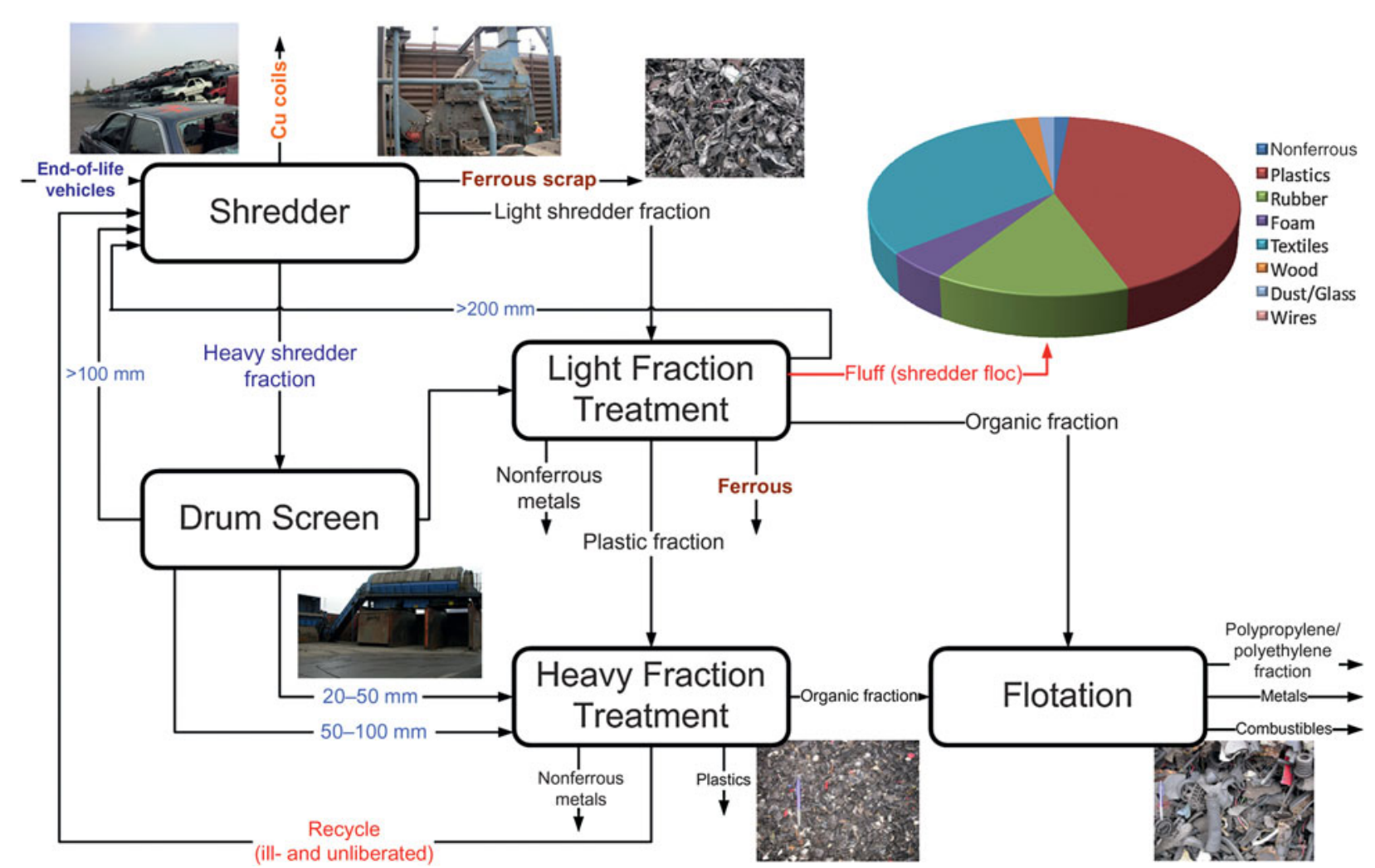

Figure 6. Overview flow sheet ${ }^{9}$ of the industrial plant and main groups of technologies that were used to recycle 1153 cars, including various main recyclate and intermediate process streams and the generalized composition of the unrecyclable fluff stream obtained after extensive treatment. Each of the elements in the numerous compounds, materials, and metals had to balance to create a consistent overall mass balance. This balance was achieved by data reconciliation incorporating all analysis standard deviations of samples of all streams, materials, and compounds. This level of detail and understanding lies at the core of quantifying recycling rates, system performance, and system improvements, as well as calibrating models.

statistically well-controlled trial, the average recycling rate for this population of cars. The trial included a statistical population of cars matching the types and ages discarded in the Netherlands at the time. The details of the methodology required to calculate recycling rates within sampling theory can be found in Reference 9. The various fractions recovered included those from depollution and dismantling; steel recovery after shredding; and recovery of metals, compounds, and materials from the light and heavy fractions through post-shredder processes including flotation. As described at the International Auto Recycling Conference in Geneva, Switzerland, in 2004, ${ }^{16}$ recoveries can easily reach values close to $86 \%$ using standard technology, and $90 \%$ recovery ${ }^{17}$ can be attained, inclusive of energy recovery, depending on the post-shredder technology available at a recycling plant, the geographical location of the plant, and national environmental legislation governing disposal.

Regardless of the technology available in the overall recycling chain, a fraction that is too expensive and complex to recycle will always remain; this fraction is represented by the fluff stream in Figure 6. Metals are usually recovered to a high degree, so little metal was left in the fluff. From the reported data, ${ }^{16}$ the fluff stream comprised around $10 \%$ after advanced post-shredder treatment, determined by the factors mentioned in the preceding paragraph. (Usually, the fluff stream is not subjected to post-shredder treatment, so it comprises more than $15 \%$ of the vehicle mass and is much dirtier.) In general, this fraction, together with all of the absorbed oils and other unprocessable wastes, has to be landfilled if technology is not available that can recover its energy content.

\section{Wastewater and surface water}

Maximizing resource efficiency requires a holistic view. Such a view links the wastewater system with its residues (sludges), for example, or surface-water systems and emission sources such as households, industrial plants, farms, and transportation networks with technological end-of-pipe solutions such as wastewater and sludge treatment processes and metallurgical processing. Recently, we explored a wastewater system in terms of ${ }^{10}$

- all substances originating from different wastewater sources, their concentrations in the different streams, and their interactions in different processes;

- input and output streams, including emissions from industry, farming, households, and traffic, and intermediate/interprocess mass flows; and

- end-of-pipe technologies for wastewater treatment plants, including interfacing with thermal treatment, minerals, and 
metallurgical processing for the recovery of specific elements from wastewater sludge and other residues created during wastewater treatment.

The model that we developed links the processing of wastewater treatment plant (WWTP) sludges and energy and material recovery with the metal, material, and waste processing systems. The pivotal role of metallurgical/mineral processing is included through the recovery of substances such as phosphorus and zinc from the WWTP sludge. On this basis, policy measures for the different stakeholders can be formulated, and WWTP and sludge processing routes can be designed. The model elucidates the link between pharmaceuticals, farming, industry and consumer behavior, and product use and highlights how species get into surface water, how they can be recovered, and how this process can be managed in the future to control water quality.

We used our water-cycle mode $1^{10}$ to provide information such as the optimal combination of input-reducing technology and policy measures into sustainability frameworks for the implementation of the European Wastewater Framework Directive for the Brabantse Delta Water Board in the Netherlands. The model also allows predictions of the required efficiency of possible future technology, such as additional wastewater processing steps. The model integrates water processing with material processing, recovery, and emissions and with energy recovery. As an example, it can be applied to predict the required wastewater treatment plant architecture, type of phosphorus removal process (biological or chemical treatment), and chemicals used in relation to the incineration of and phosphorus recovery from sludge for the most resource-efficient production of fertilizers.

\section{Summary}

Ensuring continued resource availability and material flow into sustainable products requires well-designed systems that capture these resources from end-of-life (EOL) products and recycle them into new applications. Understanding the impact of product design and recycling system performance on this closure of material cycles requires comprehensive approaches consistent with basic principles, as presented in this article.

To inform policy and design resource supply and recycling systems, one must have detailed knowledge and understanding of recycling and high-temperature processing technology, as well as the effects of product design and possible changes in products and consumer behavior. A robust system design will help maximize resource efficiency, for example, reducing landfill usage, while securing the long-term supply of metals for products in the renewable-energy and other sustainability sectors.

Ultimately, resource efficiency is determined by how well the links among products, EOL processing, recyclate quality, recycling, and metallurgical technology are understood and optimized and, thence, how much material eventually lands in landfill because its complex composition eliminates its economic value. Poor material stewardship occurs and ultimately landfills exist because of a failure to create economically viable recyclates. Although the second law of thermodynamics imposes limits on recyclability, such failures also result from avoidable mistakes such as inadequate product design, collection systems, and process optimization.

Our research and development provides a theoretical basis for understanding the minimization of waste creation and hence the environmental burden of product and metal usage. It underpins resource efficiency with a theoretical basis, which is an important tool to help maintain and safeguard resources used in manufactured products, including scarce critical elements.

The integration of systems discussed herein highlights the importance of visualizing Kaufmann's "adjacent possible,"18 that is, introducing innovations that can be achieved now while considering all possible future solutions, and thus creating an exploration platform for systems innovation. This supports a technoeconomic evaluation of systems inclusive of the physics of the systems and hence provides an enabling technology for sustainability with enough detail to reveal the opportunities and limits of recycling.

\section{References}

1. A resource-efficient Europe-Flagship initiative under the Europe 2020 Strategy [Report COM(2011) 21, European Commission, Brussels, Belgium, 2011].

2. Critical raw materials for the EU (2010): Report of the Ad-hoc Working Group on defining critical raw materials (European Commission, Brussels, Belgium, 2010).

3. M.A. Reuter, Waste Biomass Valorization 2, 183 (2011).

4. A. van Schaik, M.A. Reuter, Miner. Eng. 23, 192 (2010).

5. "About Wecycle" (Wecycle, Zoetermeer, The Netherlands, 2011), www.wecycle.eu (accessed February 2012).

6. S. Krinke, A. van Schaik, M.A. Reuter, J. Stichling, in Innovative Developments for Lightweight Vehicle Structures: Conference Proceedings (Volkswagen AG, Wolfsburg, Germany, 2009), pp. 196-208.

7. A. van Schaik, M.A. Reuter, Miner. Eng. 20, 875 (2007).

8. "SLC-SuperLIGHT-CAR: Introduction" (SLC Consortium, Project Leader Volkswagen AG, Wolfsburg, Germany, 2005-2009), www.superlightcar.com (accessed February 2012).

9. M.A. Reuter, K. Heiskanen, U. Boin, A. van Schaik, E. Verhoef, Y. Yang, The Metrics of Material and Metal Ecology, Harmonizing the Resource, Technology and Environmental Cycles (Elsevier BV, Amsterdam, 2005), vol. 16.

10. A. van Schaik, M.A. Reuter, H. van Stokkom, J. Jonk, V. Witter, Miner. Eng. 23, 157 (2010)

11. HSC Chemistry (Outotec Research Oy, Espoo, Finland, 2011), version 7.1

12. A. van Schaik, M.A. Reuter, Resour. Conserv. Recycl. 40, 301 (2004).

13. W.J. van den Hoek, G.M.J.F. Luuks, C.G.H. Hoelen, in Ullmann's Encyclopaedia of Industrial Chemistry (Wiley-VCH, Weinheim, Germany, 2010), p. 53.

14. I. McGill, in Ullmann's Encyclopaedia of Industrial Chemistry (Wiley-VCH, Weinheim, Germany, 2005), p. 46

15. A. Anindya, D. Swinbourne, M.A. Reuter, R. Matusewicz, in Proceedings of the European Metallurgical Conference EMC 2011 (GDMB, Clausthal-Zellerfeld, Germany, 2011), Vol. 1, pp. 3-14.

16. Proceedings of the 4th International Auto Recycling Congress (2004).

17. ARN Recycling: What we do (ARN, Amsterdam, The Netherlands), www.arn. nl/english/ARN-Recycling/What-we-do (accessed February 2012).

18. S. Johnson, Where Good Ideas Come From-The Natural History of Innovation (Penguin, New York, 2010). 